it is also facilitated by collisions with polarizable molecules or by van der Waals interactions in general. In other instances, quenching can be associated with chemical interaction, which often may be of an 'electron-transfer' character.

Another feature of solution luminescence is the appearance of long-lived phosphorescence or 'slow fluorescence' for many substances when they are examined at low temperatures. These effects are attributed to 'triplet' or 'diradical' excited levels of the molecule and provide information of very great importance to energy-level theory and for the elucidation of the mechanism of photochemical changes.

The luminescent phenomena of solids are proving the most difficult to interpret in spite of the heavy concentration of research on the subject. Pure fluorescent erystals at low temperatures show fine line spectra, which are even more complex than those of gases. 'The usual 'impurity activated' solid phosphors, however, err to the opposite extreme and give structureless bands of little diagnostic value. Agreement has not yet been reached on clear explanations of the nature of the absorption processes in many instances of important inorganic phosphors, on the mode of energy transfer to the 'luminescent centre', on what a 'centre' is, on the emission process, on the so-called 'traps' required to explain long-delay phosphorescence, and on the relation of 'traps' to 'centres'. These substances are usually raised to luminescence by use of a Wood's black-glass lightfilter. It almost appears as if their theoretical interpreters also view them 'through a glass darkly', or through the one-time French version of an 'écran de bois'. This obscurity must doubtless yield in time and formal jargon be replaced by molecular concepts.

The encyclopædic nature of Prof. Pringsheim's volume makes it an indispensable reference book for the student who requires either an overall picture of the subject or detailed information on any particular part. The standard of factual accuracy is very high; but many typographical errors remain for correction in a later edition.

E. J. BOWEN

\section{HANDBOOK OF METALLURGY}

\section{Metals Reference Book}

By Dr. Colin J. Smithells. Pp. xvi+735. (London : Butterworths Scientific Publications, Ltd.; New York: Interscience Publishers, Inc., 1949.) 60s. net. W WETHER metallurgy started as a branch of chemistry or whether chemistry developed from the metallurgical art there can be no doubt that in the past generation a complete re-orientation has occurred, as a result of which the linkage is now with physics. This fact is most clearly demonstrated by the general content of this really important book. That metallurgy is not, however, merely a branch of applied physics finds adequate expression in the data regarding classical crystallography and crystalchemistry, in an excellent physicn-chemical treatment of gas-metal systems and of diffusion in metals.

Normal metallographic techniques and, in particular, electrolytic polishing and etching are discussed at length, and clearly show the rapidity with which the electrolytic methods of polishing are replacing older ones. The outstanding importance of the thermal equilibrium diagram is reflected in the hundred pages devoted to the diagrams of the binary and ternary systems, and even the first stages of a few quaternary ones. It is of very great value to the metallographer to have these collected together, and, although in a few cases the diagrams are small, they provide an adequate picture of the phases and the compositions and temperatures at which changes occur.

Taken all in all, the book is the ideal treatment, with an emphasis on the basic physical properties with which the metallurgist is likely to be concerned, but yet with that firm foundation of normal metallographic outlook and fact. Further, it is no mere compilation of data ; there is throughout an adequate discussion of the subject-matter of the particular field to which the data refer. Quite apart from the more theoretical aspects to which attention has so for been mainly directed, there is, in the last third of the volume, a discussion of more immediately practical subjects, such as mechanical properties of alloys, both at ordinary and at elevated temperatures, data relating to the foundry, to heat-treatment and to refractory materials, electrolytic processes, soldering, and so on.

Under the editor, his assistants and the long list of expert contributors, one would expect to find an authoritative treatment of everything dealt with. That expectation is fully realized, and from beginning to end there is nothing either superficial or slipshod.

F. C. THOMPSON

\section{ALGEBRAIC SURFACES}

\section{Le Superficie Algebriche}

By Federigo Enriques. Pp. xv +464 . (Bologna : N. Zanichelli, 1949.) 3,000 lire.

WHEN F. Enriques died in 1946, he left an almost completed volume on algebraic surfaces which was intended to be a definitive account of his chief scientific activity. The preliminary sketches for this work had been published much earlier, in two parts, with the collaboration of L. Campedelli : the first appeared in lithographed form, in 1932, under the title, "Lezioni sulla Teoria delle Superficio Algebriche", while the sequel was issued by the Mathematical Seminar of the University of Rome two years later. During the period 1938-45 of forced retirement, Enriques gave much thought to its possible successor, which should not merely cover more ground-almost the whole of it being his own contribution-but which should also attempt to fill certain lacunæ which had made themselves evident in the preceding twenty-five years.

While the former aim has been achieved, both by an ampler account of the earlier theory and by fresh contributions from the author, the latter has, unfortunately, not been completely reslized, even though two of Enriques's pupils, Profs. G. Pompilij and A. Franchetta, have given much devoted labour to the revision of the manuscript. The serious gap in the theory is there, as it has always been, in the account of continuous systems of curves on as surface. For a whole generation the ablest geometers have devoted their attention to this question, so far without success; and in the present volume Enriques has done little more than repeat some hints, rather than proofs, towards a solution of the difficulty. $\mathrm{He}$ has added a historical sketch of the efforts that have been directed to this end, which makes interesting, if melancholy, reading. 